\title{
Elastic Analysis of Sinusoidal Cracks
}

\author{
K. Fujimoto \\ The University of Tokyo, Tokyo, Japan
}

\section{Introduction}

Most of previous analyses of cracks have been concerned with straight ones; however, under complicated boundary conditions, cracks do not propagate straight but show various propagation patterns. For example, it is well known that regular wavy crack patterns appear as shown in Fig.1 when a uniformly heated glass plate is quenched by lowering it into cold water gradually in in-plane direction [1] and in recent years, related research reports can be appreciated [2], [3]. Furthermore, it is also well known that a sinusoidal crack pattern is often observed when a high pressure gas pipe fractures [4], [5]. Figure 2 shows a sinusoidal crack path after rapid crack propagation in polyethylene pipe (British Gas full-scale test) [5] and Fig.3 is an example of fractured glass tube due to internal water high pressure [6]. Thus, sinusoidal cracks are sometimes observed in actual fractured solids. The final objective of this study is to elucidate the

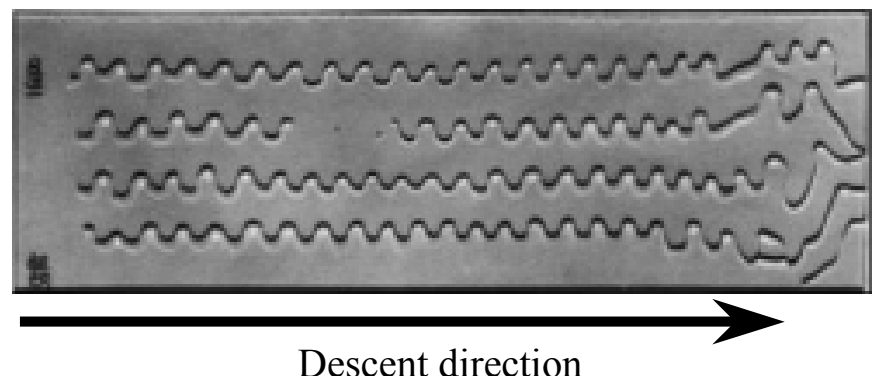

Fig.1 Sinusoidal cracks running in a thermally quenched glass plate with the width $6 \mathrm{~cm}$, the length $18 \mathrm{~cm}$ and the thickness $2 \mathrm{~mm}$. This plate was heated to $160^{\circ} \mathrm{C}$ and lowered into cold water gradually in the in-plane direction.

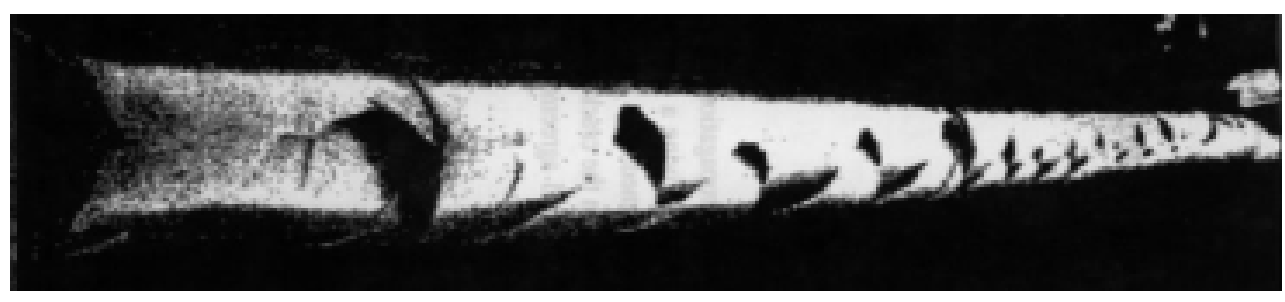

Fig.2 Sinusoidal crack path after rapid crack propagation in polyethylene pipe (British Gas full-scale test) [5]. 


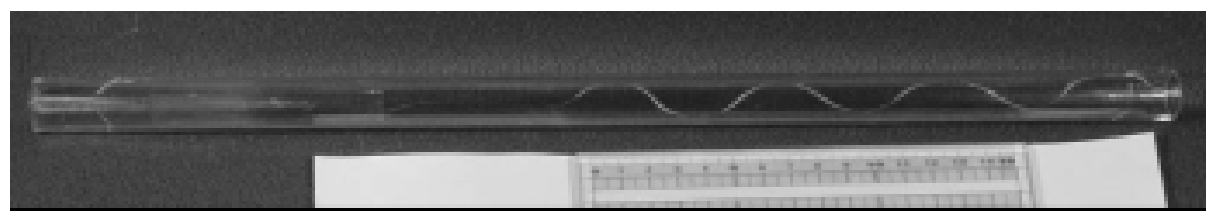

Fig.3 A sinusoidal crack running in an internally pressurized glass tube with the length $40 \mathrm{~cm}$, the external diameter $18 \mathrm{~mm}$ and the thickness $1.2 \mathrm{~mm}$. The internal water pressure on fracture was $0.23 \mathrm{MPa}$ [6].

generating mechanism of such sinusoidal cracks as shown in Figs.1-3. However, it is very difficult to achieve this final objective and it is unclear whether the generating mechanisms of these sinusoidal cracks are common to Figs.1-3 or not. In either case, detailed elastic analyses of sinusoidal cracks are needed regardless of the actual sinusoidal cracks shown in Figs.1-3. Regarding the elastic analysis of sinusoidal cracks, Lu \& Comninou [7] analyzed a single wavelength sinusoidal crack with a small amplitude under the mixed mode loading (modes I and II) considering the contact of both crack surfaces. In this paper, basic problems of sinusoidal cracks with various lengths are analyzed and the direction of crack propagation is discussed in terms of the stress intensity factors ratio $K_{\mathrm{II}} / K_{\mathrm{I}}$ using the maximum tangential stress criterion proposed by Erdogan \& Sih [8].

\section{Model of Sinusoidal Cracks}

In this study, a single sinusoidal crack shown in Fig.4 and an array of periodically situated sinusoidal cracks shown in Fig.5 are analyzed. In both models, $\sigma_{2}$ in the $x$-direction as well as $\sigma_{1}$ in the $y$-direction is applied simultaneously at infinity. The model shown in Fig. 4 is related to neither of the actual sinusoidal cracks shown in Figs.1-3 because the boundary condition of Fig.4 does not agree with either of Figs.1-3. However, the model shown in Fig.5 is regarded as the development of the glass tube shown in Fig.3. $\sigma_{1}$ and $\sigma_{2}$ can be regarded as the hoop stress due to the internal pressure of the tube and the axial stress, respectively and $h$ corresponds to the circumference of the tube. Using the method of continuously distributed dislocations model, these problems are reduced into a set of singular integral equations of the Cauchy type in which dislocation densities on the crack surfaces are unknown functions. Stress intensity factors at the crack tip A in Figs. 4 and 5 are calculated with changing the length $\alpha c$ ( $c$ : semi-wavelength of the sinusoidal crack). As the numerical method of the singular integral equations, the method proposed by the author [9] was used.

\section{Numerical Results and Discussions}

Calculated energy release rates $\mathrm{G}$ of a single sinusoidal crack (Fig.4) and an array of periodically situated sinusoidal cracks (Fig.5) are shown in Figs.6 and 7, 


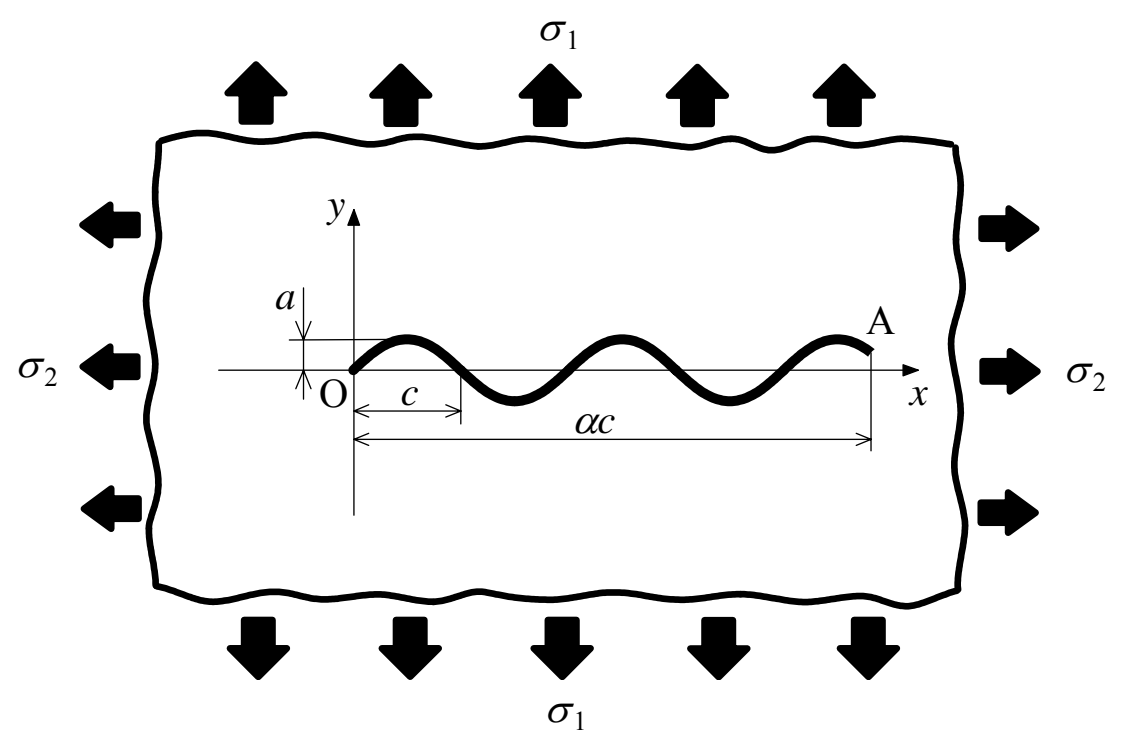

Fig.4 Model of a single sinusoidal crack.

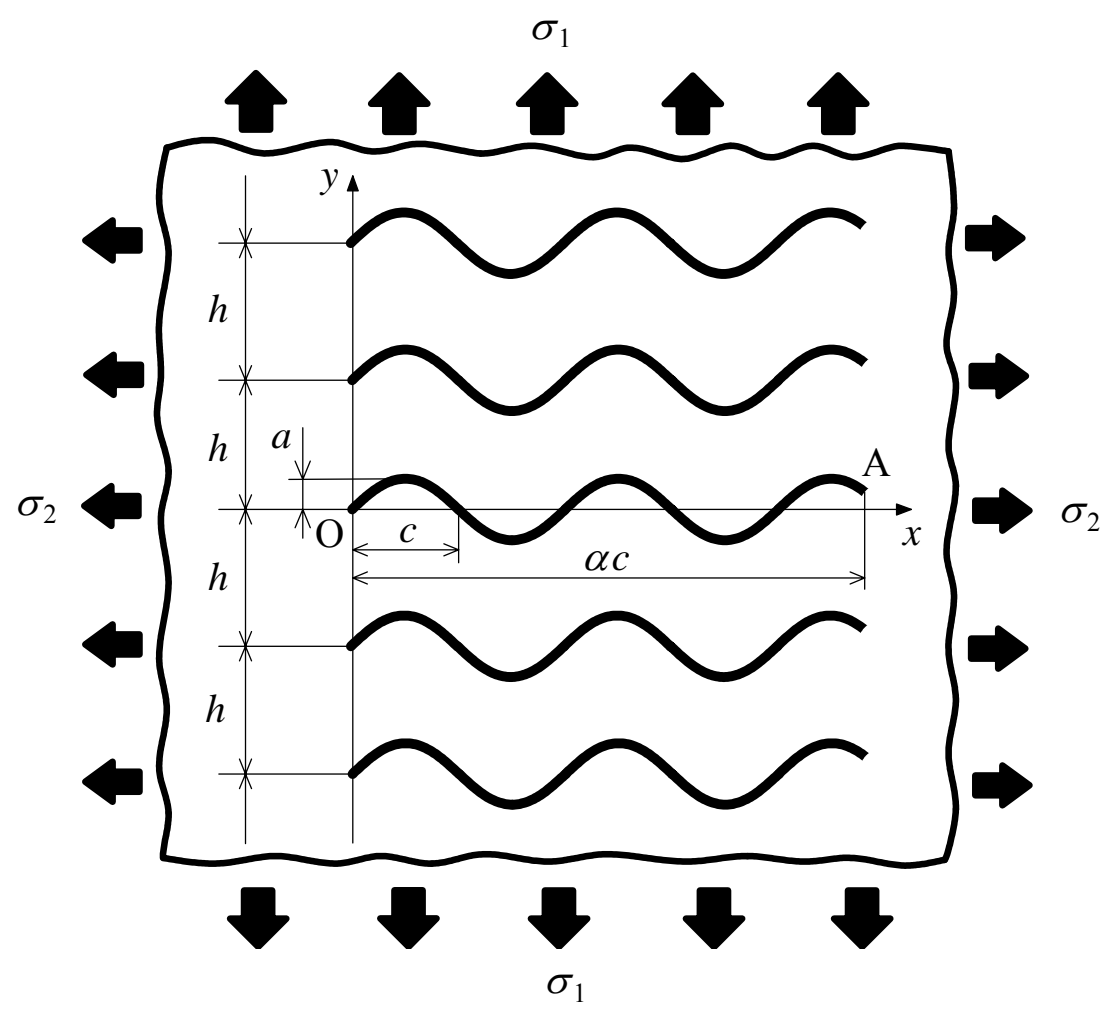

Fig.5 Model of an array of periodically situated sinusoidal cracks. 


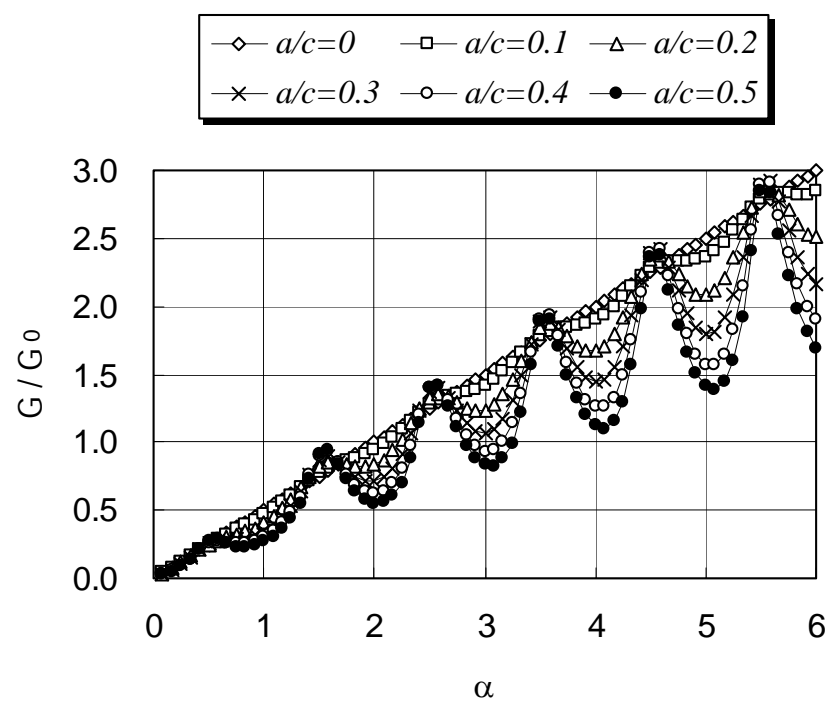

(a) $\sigma_{2} / \sigma_{1}=0$

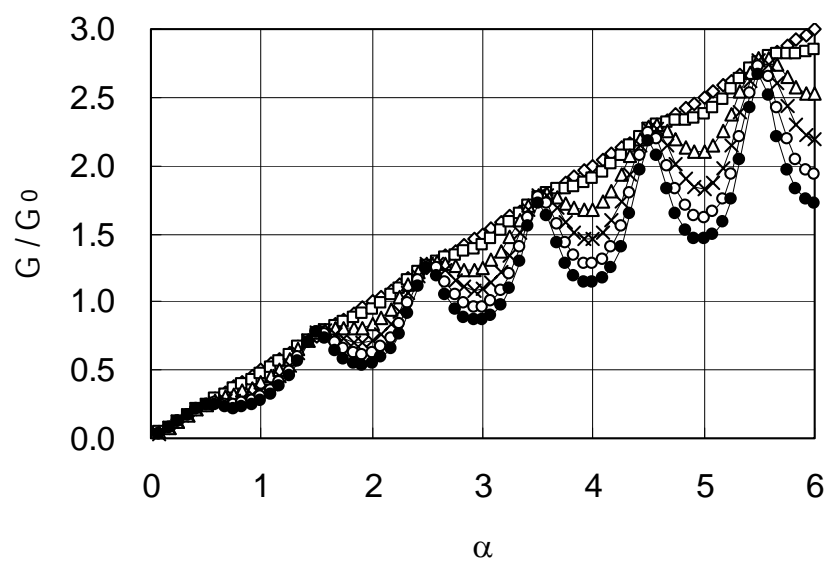

(b) $\sigma_{2} / \sigma_{1}=0.5$

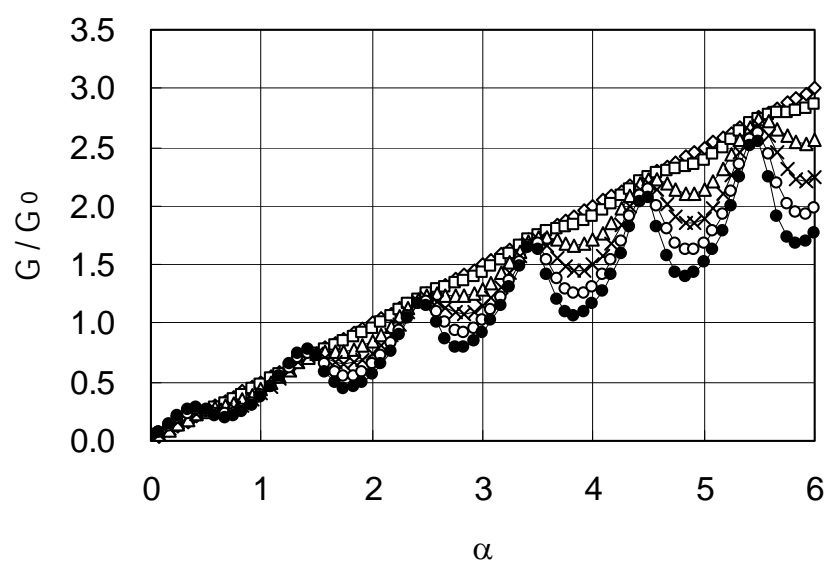

(c) $\sigma_{2} / \sigma_{1}=1$

Fig.6 Calculated energy release rate of a single sinusoidal crack. 


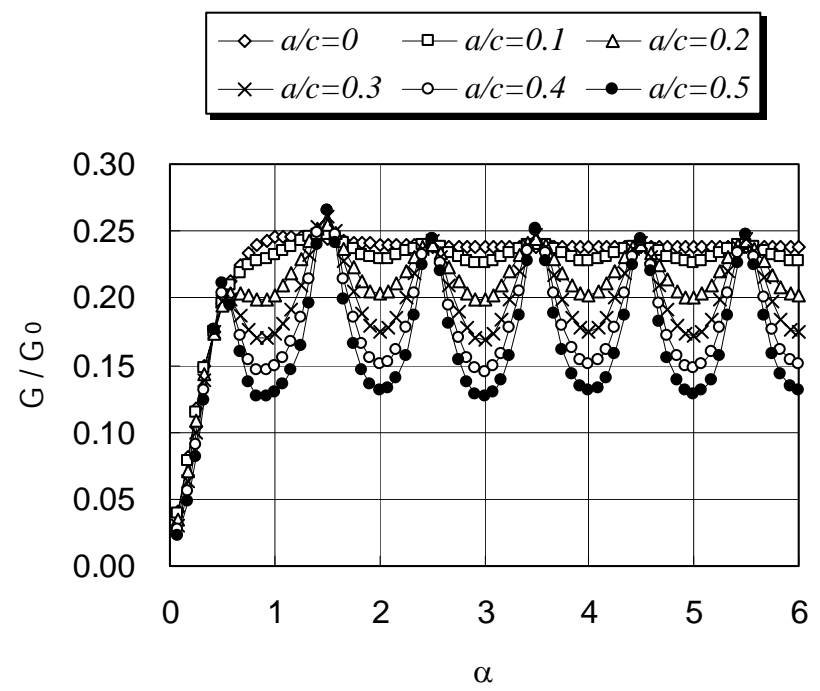

(a) $\sigma_{2} / \sigma_{1}=0$

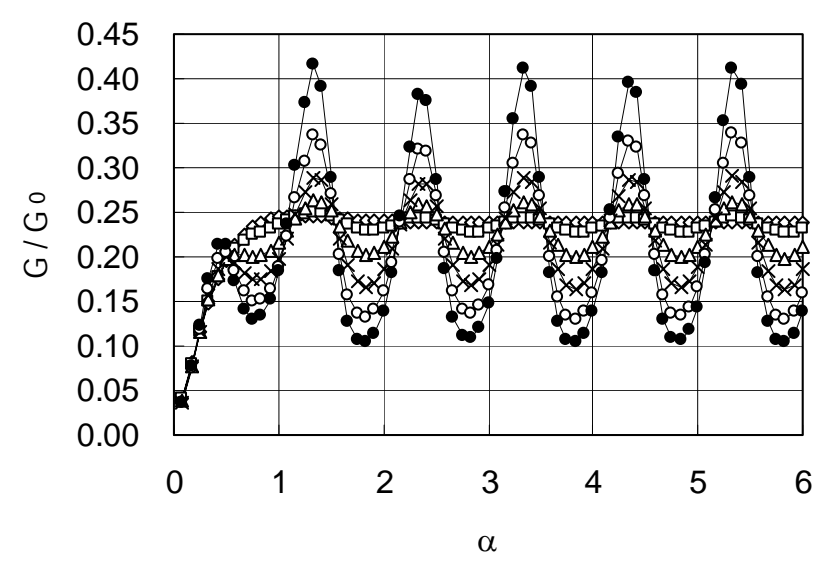

(b) $\sigma_{2} / \sigma_{1}=0.5$

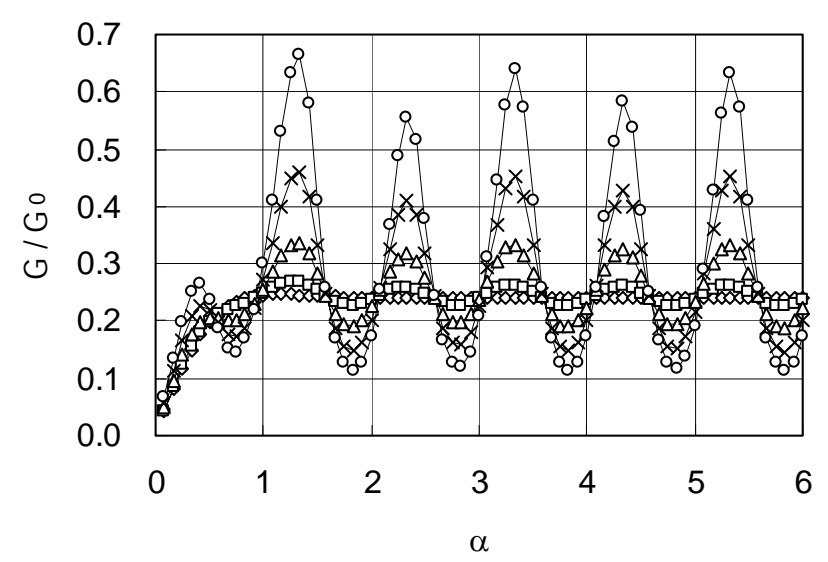

(c) $\sigma_{2} / \sigma_{1}=1$

Fig.7 Calculated energy release rate of an array of periodically situated sinusoidal cracks. 


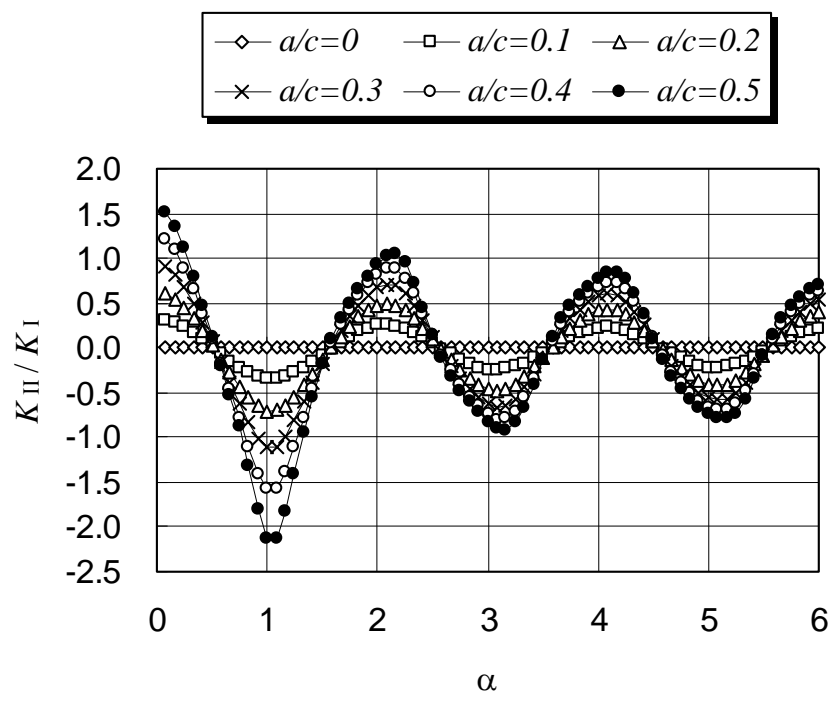

(a) $\sigma_{2} / \sigma_{1}=0$

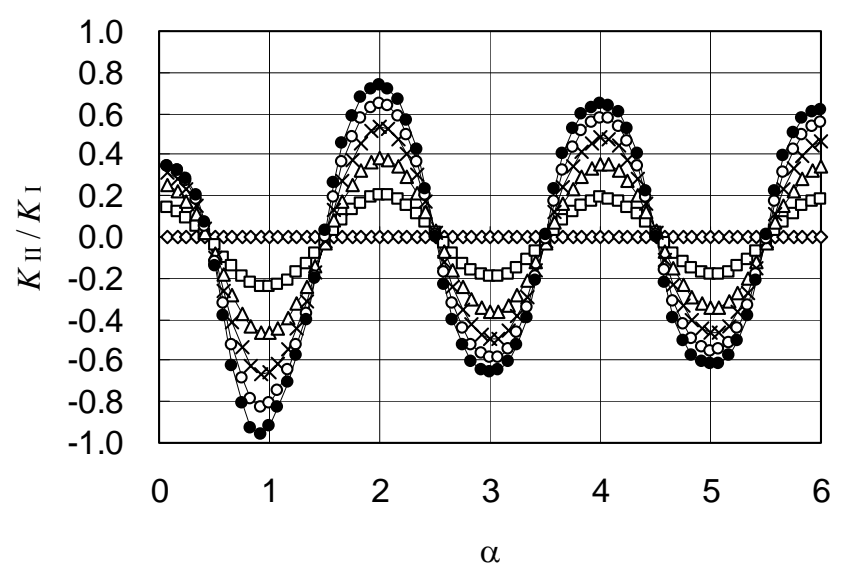

(b) $\sigma_{2} / \sigma_{1}=0.5$

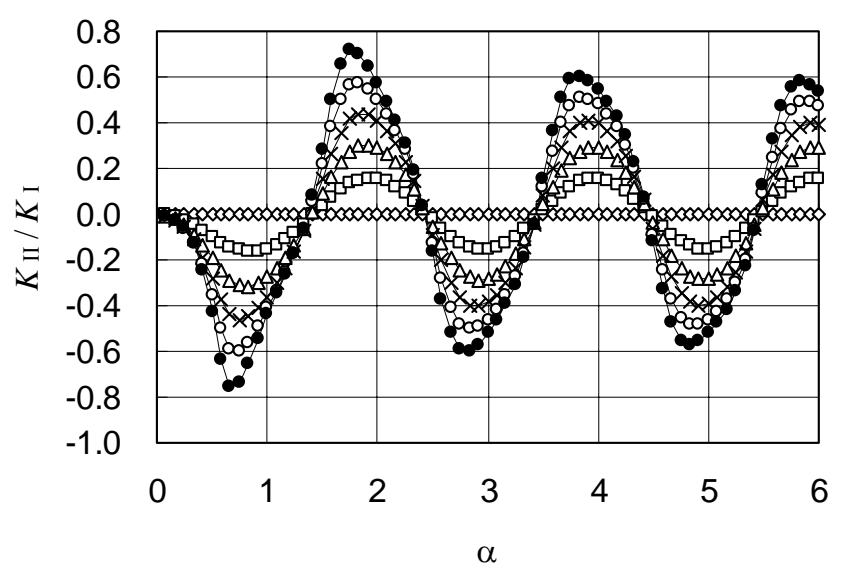

(c) $\sigma_{2} / \sigma_{1}=1$

Fig.8 Calculated stress intensity factors ratio $K_{\mathrm{II}} / K_{\mathrm{I}}$ of a single sinusoidal crack. 


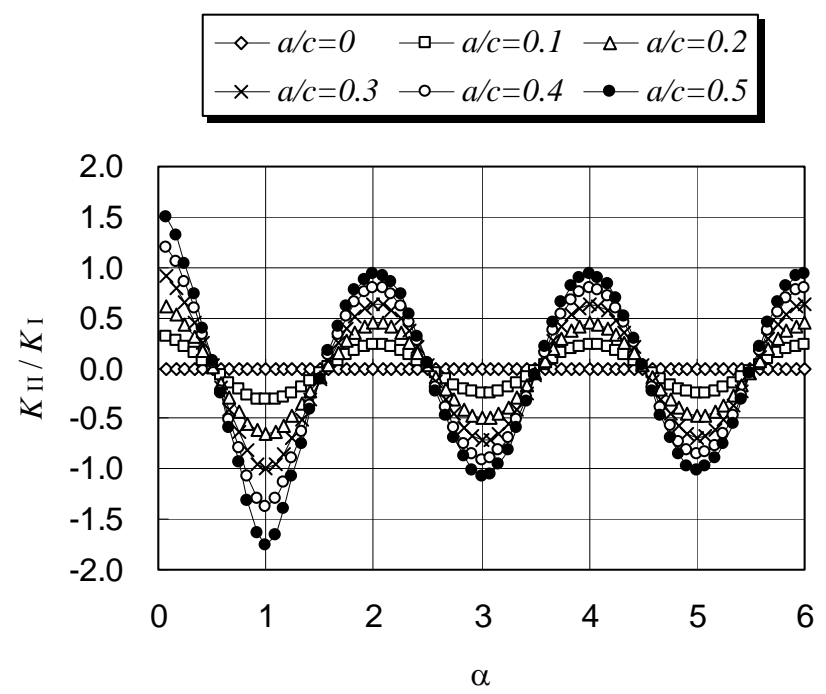

(a) $\sigma_{2} / \sigma_{1}=0$

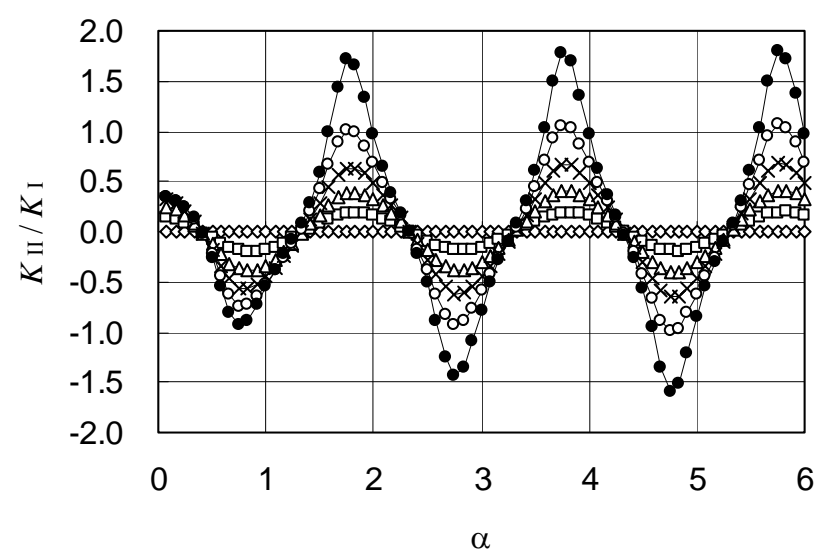

(b) $\sigma_{2} / \sigma_{1}=0.5$

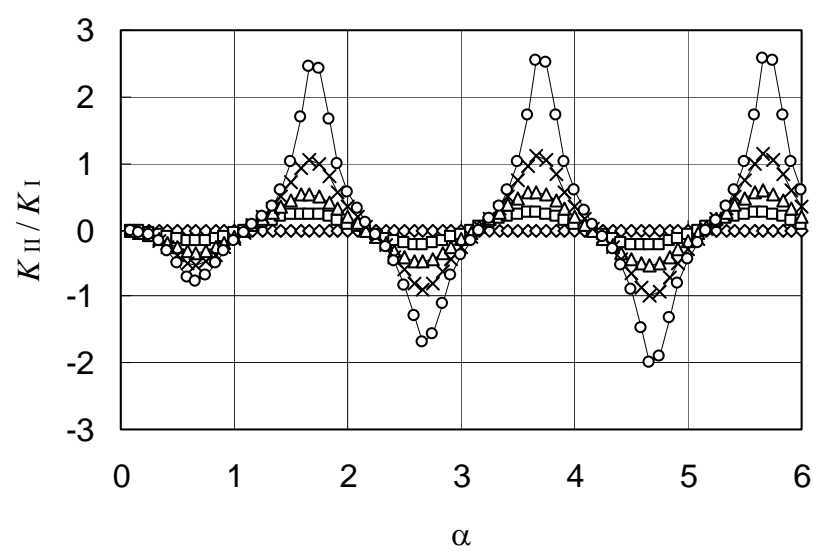

(c) $\sigma_{2} / \sigma_{1}=1$

Fig.9 Calculated stress intensity factors ratio $K_{\mathrm{II}} / K_{\mathrm{I}}$ of a set of periodically situated sinusoidal cracks. 


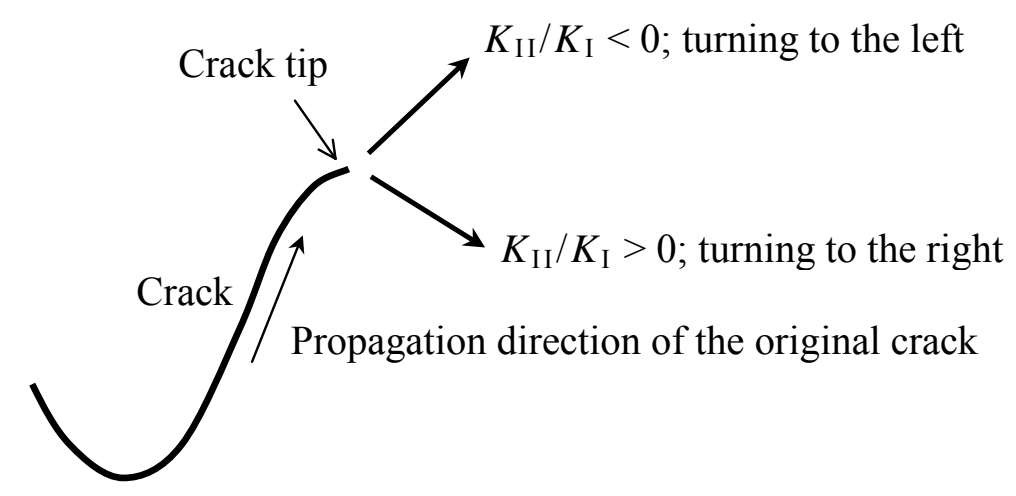

Fig.10 Propagation direction of crack tip (Maximun tangential stress criterion $[8])$.

respectively. In these figures, $\mathrm{G}$ is normalized by $\mathrm{G}_{0}$, the energy release rate when there is a single straight crack $(a=0)$ with the length $2 c$. The energy release rate is a very important parameter for investigating crack propagation, but as far as only the energy release rate is considered, it is difficult to elucidate the generating mechanism of sinusoidal cracks.

Figures 8 and 9 show the calculated stress intensity factors ratio $K_{\mathrm{II}} / K_{\mathrm{I}}$ of each model with letting the stress ratio $\sigma_{2} / \sigma_{1}$ be $0,0.5$ and 1. As shown in Fig.10, according to the maximum tangential stress criterion [8], a crack in a brittle plate is likely to propagate to turn to the right when $K_{\mathrm{II}} / K_{\mathrm{I}}>0$ and left when $K_{\mathrm{II}} / K_{\mathrm{I}}<$ 0 . The angle between the propagation direction and the original crack direction can be calculated using the value of $K_{\mathrm{II}} / K_{\mathrm{I}}$. In the case of the uniaxial tension $\left(\sigma_{2} / \sigma_{1}=0\right)$, from Figs.8-(a) and 9-(a), it can be seen that the cracks are forced to turn to the direction perpendicular to the tensile direction. However, in the case when $\sigma_{2} / \sigma_{1}=0.5$, though a single sinusoidal crack is forced to turn to the direction perpendicular to the maximum principal stress $\left(\sigma_{1}\right)$, periodically situated sinusoidal cracks are forced to increase its amplitude when the crack tip A is at $x \approx 0.5 c, 1.5 c, 2.5 c$, पर०, considering the effect shown in Fig.10. This tendency is remarkable at equi-biaxial tensile state $\left(\sigma_{2} / \sigma_{1}=1\right)$ not only in the periodically situated sinusoidal crack model but also in the single sinusoidal crack model. Therefore, it may be possible to say that the biaxial tension plays an important role in the generation of the sinusoidal cracks. However, the snaking mechanism is not still clear.

\section{Conclusion}

In this study, sinusoidal cracks were analyzed and the calculated energy release rate and stress intensity factors ratio $K_{\mathrm{II}} / K_{\mathrm{I}}$ are shown. Using the numerical results, the direction of crack propagation was investigated by the maximum tangential stress criterion. As the results, it was suggested that there is a tendency that the crack is forced to propagate to the direction increasing the amplitude of 
sinusoidal crack under biaxial tensile state. However, the reason of the crack snaking has not been clarified by this theory based on stress intensity factors.

\section{References}

[1] M. Hirata, "Experimental studies on form and growth of cracks in glass plate", Scientific Papers of the Institute of Physical and Chemical Research, Tokyo, Vol.16, No.322, 1931, pp.172-195

[2] K. Fujimoto, S. Ishida, H. Taguchi, K. Horiike, "Fundamental study on crack propagation (on the crack appearing when uniformly heated glass plate is descended into cold water gradually)", Proceedings of the 34th Annual Meeting of the Japan Society of Technology Education, Joetsu, Japan, 1991, p.51 (in Japanese)

[3] A. Yuse, M. Sano, "Transition between crack patterns in quenched glass plates", Nature, Vol.362, 1993, pp.329-331

[4] R.W.E. Shannon, A.A. Wells, "Brittle crack propagation in gas filled pipelines using thin walled unplasticised PVC pipe", International Journal of Fracture, Vol.10, No. 4, 1974, pp.471-486

[5] J.G. Williams, G.P. Venizelos, "A perturbation analysis of rapid crack propagation in pressurised pipe", International Journal of Fracture, Vol.94, 1998, pp.161-176

[6] K. Fujimoto, T. Shioya, "Wavy crack propagation in internally pressurized glass tube", Proceedings (CD-ROM) of the 11th International Conference on Fracture, Turin, Italy, 2005, Article No.4104

[7] X. Lu, M. Comninou, "The sinusoidal crack", Engineering Fracture Mechanics, Vol.34, No.3, 1989, pp.649-656

[8] F. Erdogan, G.C. Sih, "On the crack extension in plates under plane loading and transverse shear", Transactions of ASME, Journal of Basic Engineering, Vol.85, 1963, pp.519-527

[9] K. Fujimoto, "Method of numerical analysis of the singular integral equations for crack analysis", JSME International Journal, Series I, Vol. 34, No. 4, 1991, pp.430-435 